\title{
Benefits of night temperature setback in the control strategy of the district heating system
}

\author{
Viliam Dolinay ${ }^{1 . *}$, and Lubomir Vasek $^{1}$ \\ ${ }^{I}$ Tomas Bata University in Zlin, Faculty of Applied Informatics, Nad Stranemi 4511, 76005 Zlin, Czech Republic
}

\begin{abstract}
Reducing heating system performance by applying a temperature setback as a means of saving heating costs is a well-known and widely used practice. There are discussions about setback achievements, especially about the amount of real savings it brings. However, it is not easy to declare any number - a percentage, because not only most of the heated objects are different, but especially the effects that affect them - from the location of building to demand and user behavior. In real life, heat consumers apply different setbacks to their heating systems, that is a fact, and from the heat supplier's point of view, it is desirable to adopt this consumer behavior and plan a central heat supply more efficiently with a view to this fact. This article focuses on this issue. It shows the results of a practical experiment that took place in the heating season 2018/2019 in the local district heating system. The experiment carried out was that half the heating season was the temperature of the heating water determined only based on the heating curve coming from the current outdoor temperature, and for the second half of the season was applied night setback - for 5 hours every day, the temperature was lower by $10 \%$. Evaluating the experiment showed a decrease in the demanded heat of about $8 \%$ compared to the first part of the heating season. All this savings cannot be unambiguously attributed to the applied setback, because every part of the heating season has its specifics, but as the article shows a value of about $2.4 \%$, it seems real. Contribution in the range of several percent may not at first glance seem attractive, but if we consider that the introduction of the setback procedure does not usually mean extra cost and also the district heating systems require to deliver daily hundreds of gigajoules of the heat (considering a small town), each saved percentage has its value. At the same time, this article highlights other minor improvements that could introduce additional, maybe small but perhaps exciting savings.
\end{abstract}

\section{Introduction}

Heating is the largest single energy end-use in Europe, and it is responsible for approximately $50 \%$ of total final energy consumption. Taking an average dwelling in Europe as an example, $68 \%$ of its total energy demand is used for satisfying space heating needs and $14 \%$ for producing warm water [1].

Europe and the whole advanced world has a vision for further development in the district heating (DH) [2], but putting it into practice is slow, and it is essential to think about the efficiency of current, used technologies and how to make it a little bit better. Often, a simple adjustment is enough, and the effect will come.

\section{Temperature setbacks}

A temperature setback is a simple strategy to help save utility cost. This is achieved by allowing the temperature to drift to a lower (heating mode) or higher (cooling mode) temperature. Of course, most people want to feel comfortable when they are in their homes, workplaces, schools, etc. So allowing the temperature to drift in areas where people are active is typically unfavorable. The best approach to implementing a setback strategy is to allow the temperature to drift when space is not occupied [3].

Households - some households have set schedules where residents are gone a portion of the day. Applying a setback during these vacant periods would eliminate concerns of discomfort while reducing utility usage. Another popular approach to implementing setback that can apply to most households is to allow the temperature to drift when the occupants are asleep. This concept is called night-setback and allows the temperature drift to occur without too much notice from the occupants [3].

In general, other areas such as schools, offices, etc. also have set schedules depending on the time when they are occupied. This time is usually different from setback time in households.

\subsection{Heating-up phase}

Setback, applied for a part of the day ends ones, and then space needs to be heated back to the original level. The energy that space lost because of its coolness during the

\footnotetext{
Corresponding author: vdolinay@utb.cz
} 
setback must be substituted. It is not just air room temperature, but during a setback, all the apartment components, such as furniture, interior and especially exterior walls lower its temperature - lost heat.

This article, however, will not judge the benefits of setback - how much savings it actually brings. This is a topic for a longer discussion. If interested, see for example [4].

\section{Influence on the central heat source}

Let's take a closer look at the situation in buildings that are heated by the DH. In these buildings, regardless of the fact that they use a central heat source, a setback for the room/apartment is in the hands of a man who has a thermostat under control. Many people experiment with setting their thermostat, not only to feel comfortable in their apartment but to relieve their wallet when paying bills for heat. In this way, the individual consumer affects the temperature in his apartment by twisting the flow into the radiators, but it is optimal to regulate the heating qualitatively and quantitatively, i.e., not only by the amount but also by the temperature (quality). A person living in an apartment house does not affect the temperature of the water entering the radiators as easily as its amount. The temperature is determined by the common setting of the house station. That is why most of the houses have also set setback centrally on their home station.

However, DH is not just the supply of residential houses; the recipients of heat are schools, offices, shops, etc. Moreover, these objects, as stated above, have their own time schedules when they want to start and end setback. For example, schools reduce heating performance with the approaching departure of the students, already at the beginning of the afternoon. They apply a long setback during the weekends, and this is associated with higher demand for heat to recover the desired temperature condition before the start of the new. However, how should a central source deal with the different behavior of individual customers? Is it possible and meaningful for the source to apply setback? And if so, at what time and how big?

\subsection{What needs to be taken into account}

As the questions from the end of the previous chapter suggested, setting a setback on the source is much more complicated and seems to be more about finding a compromise solution. The central source must take into account at least the following facts:

- the change in water temperature reaches the consumer up to a certain time - caused by traffic delays. This delay is often within hours,

- there is also a traffic delay between customers spread out over a heated area. The difference between the times a change reaches the closest customer since reaching the farthest is often within hours.

\section{Practical experiment}

In this year's heating season, an experiment was conducted on a source for a small DH system. Most typical consumers are included in this selected $\mathrm{DH}$. Residential apartment houses predominate, but there are several restaurants, shop, office buildings, health center, retirement home, and school. Most of these consumers apply their own temperature setback through their home stations. This experiment did not interfere with individual house station settings, but he focused on a central source that supplies them all. The outlet water temperature from this source, for the first half of the heating season, was controlled only by the temperature curve (dependence on outdoor temperature). For the second half of the heating season, a temperature setback of $-10 \%$ from the temperature curve value was included in its control. The setback was applied every day weekdays and weekends. Its start was set at 19:30 and ends at 0:30. Time interval selection takes into account the following properties:

- the average traffic delay between the source and the foot of the city (first consumers) is about 2 hours,

- residential houses, which predominate in the locality, have its own setback set approximately from 22:00 to 5:00.

The requirement here was that the cooler water from the source arrived at the closer consumer group before they start their setback and into the more remote places it gradually flowed.

The end of the setback was also considered on the same principle - the standard water temperature must start to flow from the source in advance so that it is already in most of the consumer's house stations when their setback ends.

\subsection{Measured data}

This paragraph will show the differences in the behavior of outlet water temperature control during the experiment. The best way to see it is to compare similar temperature period from both parts of the experiment. Figure 1 shows outside temperature in a given area from 18.1.2019 to 21.1.2019 (without setback) and from 22.2.2019 to 25.2.2019 (with setback). A similar period even starts on the same day of the week - Thursday.

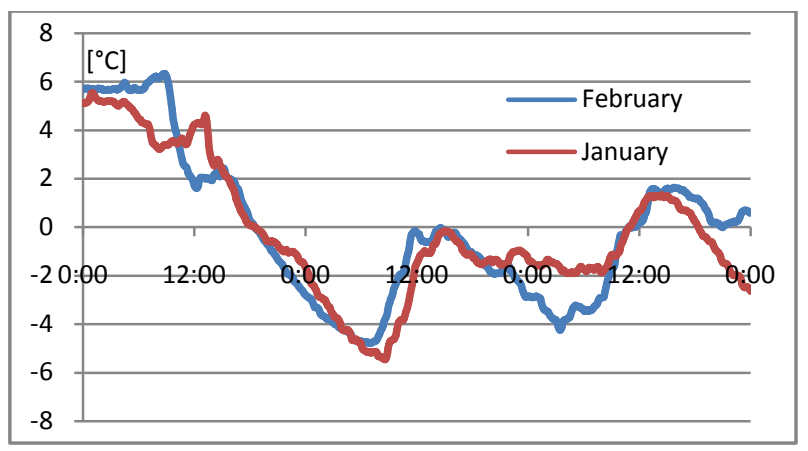

Fig. 1. The outdoor temperature in comparison days. 


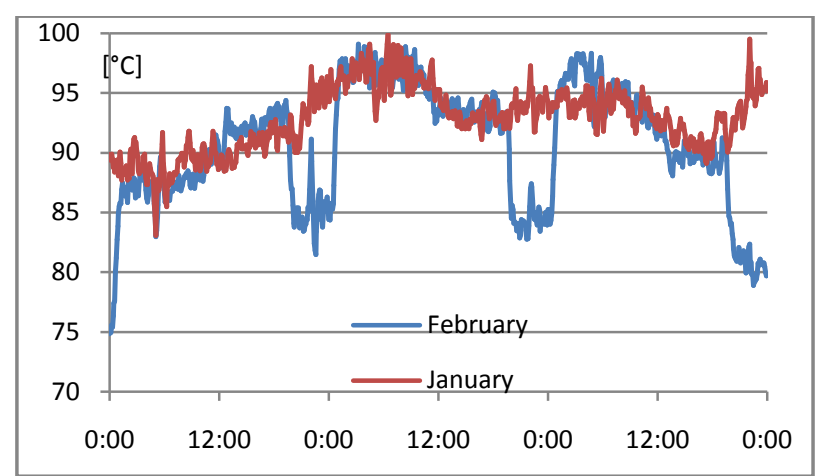

Fig. 2. Outlet water temperature in comparison days.

Figure 2 shows the outlet water temperature from the source. On the blue curve goes to see applied night setback.

Figure 3 shows the behavior measured at the home station of one of the apartment buildings in a heated location. When compared to Figure 2, the effect of the traffic delay is well visible.

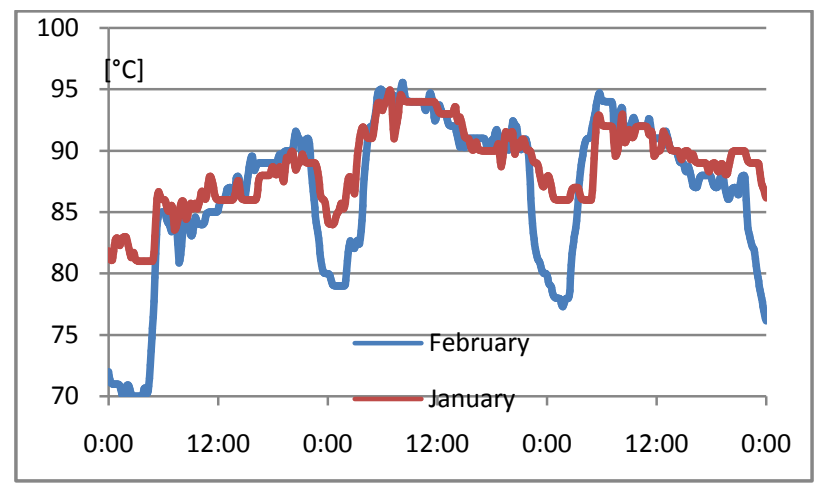

Fig. 3. Home station inlet water temperature

\subsection{Analysis of results}

The experiment aimed to verify how the heating system will respond if night-setback is applied. The comparison was made by evaluating the dependence of average daily heat consumption versus the average daily temperature in both parts of the season. The results are shown in Figure 4.

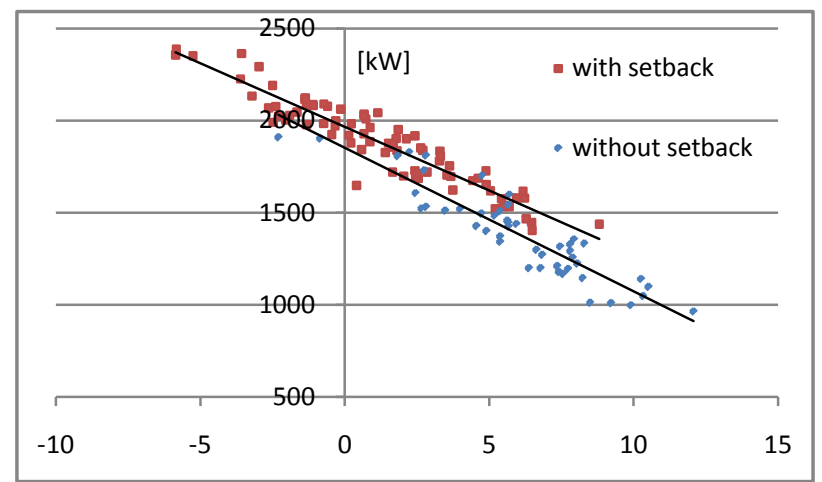

Fig. 4. Dependence of the average daily consumption on the average daily outdoor temperature.

\subsection{Evaluation of results}

Figure 4 shows a dependence of the average daily consumption on the average daily outdoor temperature in the part of the heating season when the night setback was not applied (red marks), and in part it was (blue marks). The difference (setback saving) is seen when comparing the linear dependence of the displayed values.

Specifically, for the $3^{\circ} \mathrm{C}$ (average temperature of the whole observation period), the average saving was 139 $\mathrm{kW}$. If considered a daily consumption (for the selected average daily temperature) about $1758 \mathrm{~kW}$, the savings are about $8 \%$.

However, it would not be correct to make conclusions based on one evaluation method. It can be assumed that the difference in normalized consumption would be observed, for example, between January and February, even if the temperature control method did not change, because the nature of the weather has its specifics, linked to consumption, for every part of the winter season. Of course, it is not possible to repeat the elapsed period with another method of temperature control without being able to travel in time. A simulation experiment would also be an option, but there is currently no tool that would easily make such an attempt, and a simulation error would already obstruct the results. Another option that has been used is to try to get a method error for the period when the same temperature control algorithm was used. Thus, the first half of the heating season was divided into two parts, and these parts were compared in the same way as the non-and setback parts. The same was also done for the second half of the season.

As expected, there were also noticeable differences. A summary and comparison are shown in Table 1.

Table 1. Comparing the differences between parts of the observed heating season.

\begin{tabular}{|l|r|}
\hline \multicolumn{1}{|c|}{ Conditions } & Deviation \\
\hline $\begin{array}{l}\text { Two parts during the season when night- } \\
\text { setback was not applied }\end{array}$ & $5.6 \%$ \\
\hline $\begin{array}{l}\text { Two parts during the season when night- } \\
\text { setback was applied }\end{array}$ & $5.5 \%$ \\
\hline $\begin{array}{l}\text { The part when setback was applied and the } \\
\text { part when it wasn't }\end{array}$ & $8 \%$ \\
\hline
\end{tabular}

When assuming that the heat consumption varies in the order of $5.6 \%$, it can be said, that if the night-setback algorithm applied, approximately $2.4 \%$ of the savings were achieved, which is on average 35 GJ per day. When considering the current selling price of heat, saving in the observed area was around 20 thousand euros per month. The price of production is not known to us, but it is clear, that for the heat producer is the benefit lower, but not negligible. 


\section{Conclusion}

As the article showed, applying the known methods into practice can bring interesting benefits. As practice also shows, there are still plenty of central heat sources that use only the temperature curve to control outlet temperature, regardless of the specificities of the location they are supplying. The temperature curve at the source still has a few weak points that are worth analyzing. The weak point is, for example, traffic delay from a temperature point of view. If the outlet temperature from the source is set according to the current ambient temperature, then this water is actually flowing to the consumers in the order of several hours, and then it is usually a different temperature outside (consumers also use it for their regulation). Another example of weak point is weekdays and weekends behavior of the consumers. We will address these issues in some of our other articles.

This work was supported by the Technology Agency of the Czech Republic within the project No. TH02020979 (Distributed control system for regional heat and cooling supply conceived as Smart Energy Grid)

\section{References}

1. DHC + Technology Platform, District Heating \& Cooling a VISION towards 2020 - 2030 - 2050, Available from: https://www.euroheat.org/dhc/

2. Lund, H., Werner, S., Wiltshire, R., Svendsen, S., Thorsen, J. E., Hvelplund, F., Mathiesen, B. V., Energy, 68, p. 1-11 (2014)

3. Volk. R., Morrissey Engineering Inc., Benefits of Temperature Setback in Residential Applications, Available from: https://www.morrisseyengineering.com/blog/17

4. Sense and nonsense of night set-back, Available from: http://www.ahok.de/en/night-set-back.html 